\title{
Reliable Ala-Tragus Line for the Orientation of Occlusal Plane by Cephalometry
}

\author{
Shrestha L 1* $^{*}$ Joshi S P 2 \\ ${ }^{1}$ Lecturer, Department of Prosthodontics, Kathmandu Medical College, Duwakot, Bhaktapur \\ ${ }^{2}$ Professor, National Academy of Medical Sciences, Bir Hospital, Kathmandu
}

\begin{abstract}
Introduction: The aim of the study was to determine the most reliable ala-tragus line for the orientation of the occlusal plane in edentulous patients during complete denture fabrication by cephalometry.

Materials and Methods: Lateral cephalometric radiographs of 37 dentate subjects were taken at maximum intercuspation. Steel balls were used as radio opaque markers which were adhered to superior border, middle point, and inferior border of tragus as well as the inferior border of ala of nose. Lead foil was cemented to cover the mesio-palatal cusp of maxillary first molar. Tracings of cephalogram were done. Angle between ala-tragus superior, ala-tragus middle and ala-tragus inferior in relation to occlusal plane were measured. Variables were determined and data were analyzed using SPSS version 17 (SPSS, Inc. Chicago, III).

Results: The angle formed between occlusal plane and ala tragus middle had lowest mean value of $2.39^{\circ}$. The highest was measured with ala tragus superior $5.18^{\circ}$, while the angle formed with ala tragus inferior was $3.60^{\circ}$. The differences between the three planes in relation to the occlusal plane were significantly different in total subjects as well as in both males and females $(p<0.001)$.

Conclusion: Statistical analysis showed that the middle point of the tragus with the inferior border of the ala of the nose was most accurate in orienting the occlusal plane.
\end{abstract}

Key words: Camper's plane, occlusion, complete denture

\section{Introduction}

$I^{\prime}$ $n$ both natural and artificial dentitions, the plane of occlusion plays important role in fulfilling function and esthetics. Orientation of occlusal plane is lost in edentulous patients. This should be relocated during complete dentures fabrication for optimal esthetic and functional achievement. ${ }^{1}$ Occlusal plane, anteriorly is oriented to fulfill requirement of esthetics and phonetics, and posteriorly for the purpose of mastication. ${ }^{2}$ During teeth arrangement, it is generally advised that artificial teeth be placed in positions previously occupied by natural teeth. ${ }^{1}$ Faulty orientation of occlusal plane will jeopardize interaction between tongue

\section{*Corresponding Author}

Dr. Lajana Shrestha, Lecturer, Department of

Prosthodontics, Kathmandu Medical College,

Duwakot, Bhaktapur

Email:lajanashr@gmail.com and buccinators and result in food collection in sulcus and biting of cheek or tongue. ${ }^{3}$ If the plane is higher posteriorly than anteriorly, it produces a forward thrust on upper denture, and a backward thrust on lower denture leading to looseness of bases, soreness and destruction of bony foundation.

There are various methods that utilize intraoral and extra oral landmarks for orientation of occlusal plane, and the most widely used is ala tragus line method. ${ }^{4}$ GPT- 9 defines ala tragus as "a line running from the inferior border of the ala of the nose to the superior border on the tragus of the ear; it is frequently used, with a third point on the opposing tragus, for the purpose of establishing the ala-tragus plane; ideally the ala-tragus plane is considered to be parallel to the occlusal plane". ${ }^{5}$ However, there are some controversies on the exact points of reference of ala-tragus line. ${ }^{6}$ 
The aim of the present study was to define the best posterior reference point of ala-tragus line for orientation of occlusal plane for complete denture fabrication.

\section{Methods}

Ethical approval for the study was obtained from Institutional Review Board, National Academy of Medical Sciences, Bir Hospital. This cross-sectional study was done among dentate patients visiting dental department of Bir Hospital. Thirty seven participants (19 males, 18 females) meeting the inclusion criteria: Angle's Class I molar relation, normal over jet and over bite with pleasing profile, presence of all anterior and posterior teeth up to $2^{\text {nd }}$ molar, tooth size and anatomy of normal size and development, ages between 20-35 years without any large dental caries/cavities or restoration on occlusal surface or incisal edges of teeth, without crowns or bridges or any prosthodontic rehabilitation of teeth and with no history of orthodontic treatment were randomly selected. Written informed consents were obtained from the participants. Adhesive tapes of $3 \mathrm{~mm}$ diameter were taken to which metallic balls were adhered with Cyanoacrylate cement. The tapes were adhered to superior, middle and inferior border of right tragus and lower border of ala of nose in the right side. Lead foil of $5 \mathrm{~mm}$ diameter was adhered to cover mesio-palatal cusp of right maxillary first molar using Zinc phosphate cement. Lateral Cephalograms of the participants were made from Carnex Excel Ceph at maximum intercuspation with the lips and rest of the body relaxed. Using Cephalostat, participant's head was fixed bilaterally by ear rod and anteriorly by a plastic stopper on bridge of the nose. The ear rods were inserted into external auditory meatus with appropriate care to prevent tragus from being forced anteriorly by direct pressure. The cephalometric radiographs (Figure 1) were traced manually onto acetate tracing sheets over an illuminated viewing box by using the standard technique. All radiographs were traced by the author on an average of 5 tracing per day to reduce errors due to fatigue. The angular measurements were made with a large protractor to the nearest 0.5 degrees (Figure 2).

The cephalometric points that were used in this study were the following:

Ala (A): lower border of ala of nose represented by center of radiopaque shadow of steel ball attached to lower border of right ala of nose.

Tragus superior (Ts): Superior border of tragus of ear represented by center of radiopaque shadow of steel ball attached to superior border of tragus of ear.

Tragus middle (Tm): Middle point of tragus of ear represented by center of radiopaque shadow of steel ball attached to mid-point of tragus of ear.

Tragus inferior (Ti): Inferior border of tragus of ear represented by center of radiopaque shadow of steel ball attached to inferior border of tragus of ear.

I: Lowest point of incisal edge of maxillary central incisor.

MP: Lowest point of radiopaque shadow of lead foil placed over Mesio-palatal cusp of maxillary right rst molar.

The cephalometric planes and lines used in this study were the following:

Ala-tragus line Superior (ATs): Line joining point A with point Ts.

Ala-tragus line Middle (ATm):Line joining point A with point Tm.

Ala-tragus line Inferior (ATi):Line joining point A with point Ti.

Occlusal plane (OP): Line connecting lowest point of incisal edge of maxillary central incisor (I) with lowest point of Mesio-palatal cusp of right maxillary rst molar. 
The angles that were studied are the following:

ATs-OP: Angle between ATs and Occlusal plane.

ATm-OP: Angle between ATm and Occlusal plane.

ATi-OP: Angle between ATi and Occlusal plane.

Data were entered in SPSS (Statistical package for social science) program version 17 (SPSS Inc., Chicago, III) to calculate mean and standard deviation of all the angular measurements for whole sample and for both the genders.

\section{Results}

In total subjects, angle formed between OP and ATm had the lowest mean value of $2.39^{\circ}$ and highest was measured with ATs $\left(5.18^{\circ}\right.$, while the angle formed with ATi was 3.60'. The angle between OP with ATs, ATm and ATi for males and females is depicted in Table 1.

There was statistically significant differences between the three planes i.e., ATs, ATm and ATi in relation to the occlusal plane $(p<0.001)$ in total subjects (Table 2) and in both males and females (Table 3). In $66.67 \%$ of the participants, the least angular value was measured with ATm.

Table 1: Angle between occlusal plane and ATs, ATm, ATi in Male and Female in degrees.

\begin{tabular}{|c|c|c|c|c|c|c|c|c|}
\hline \multicolumn{4}{|c}{ Male (N=19 ) } & \multicolumn{4}{c|}{ Female (N=18) } \\
\hline Parameter & Minimum & Maximum & Mean & $\begin{array}{c}\text { Std. } \\
\text { Deviation }\end{array}$ & Minimum & Maximum & Mean & $\begin{array}{c}\text { Std. } \\
\text { Deviation }\end{array}$ \\
\hline ATs-OP & 0.50 & 9.50 & 4.74 & 2.87 & 2.00 & 11.00 & 5.67 & 2.52 \\
\hline ATm-OP & 0.00 & 6.00 & 2.66 & 1.64 & 0.00 & 7.00 & 2.11 & 1.84 \\
\hline ATi-OP & 0.00 & 10.00 & 3.74 & 2.75 & 1.00 & 9.00 & 3.47 & 2.16 \\
\hline
\end{tabular}

Table 2: Difference between ATs-OP, ATm-OP, ATi-OP by predicting the $p$-value $(<0.001)$ in total subjects.

\begin{tabular}{|c|c|c|c|c|}
\hline \multicolumn{5}{|c|}{ Test Value $=0$} \\
\hline & \multirow{2}{*}{ Mean Difference } & \multicolumn{2}{|c|}{ 95\% Confidence Interval of the Difference } & \multirow{2}{*}{$\mathbf{p}$} \\
\hline & & Lower & Upper & \\
\hline ATs-OP & 5.19 & 4.29 & 6.09 & $<0.001$ \\
\hline ATm-OP & 2.39 & 1.81 & 2.97 & $<0.001$ \\
\hline ATi-OP & 3.61 & 2.79 & 4.42 & $<0.001$ \\
\hline
\end{tabular}

Table 3: Difference between ATs-OP, ATm-OP, ATi-OP by predicting the $p$-value $(<0.001)$ in Males and Females.

\begin{tabular}{|c|c|c|c|c|c|c|c|c|}
\hline \multicolumn{9}{|c|}{ Test Value $=0$} \\
\hline \multicolumn{5}{|c|}{ In Males } & \multicolumn{4}{|c|}{ In Females } \\
\hline & \multirow[t]{2}{*}{$\begin{array}{c}\text { Mean } \\
\text { Difference }\end{array}$} & \multicolumn{2}{|c|}{$\begin{array}{l}\text { 95\% Confidence Interval } \\
\text { of the Difference }\end{array}$} & \multirow[t]{2}{*}{$\mathbf{p}$} & \multirow[t]{2}{*}{$\begin{array}{c}\text { Mean } \\
\text { Difference }\end{array}$} & \multicolumn{2}{|c|}{$\begin{array}{l}\text { 95\% Confidence } \\
\text { Interval of the } \\
\text { Difference }\end{array}$} & \multirow[t]{2}{*}{$\mathbf{p}$} \\
\hline & & Lower & Upper & & & Lower & Upper & \\
\hline ATs-OP & 4.74 & 3.35 & 6.12 & $<0.001$ & 5.67 & 4.41 & 6.92 & $<0.001$ \\
\hline ATm-OP & 2.66 & 1.87 & 3.45 & $<0.001$ & 2.11 & 1.20 & 3.02 & $<0.001$ \\
\hline ATi-OP & 3.74 & 2.41 & 5.06 & $<0.001$ & 3.47 & 2.40 & 4.55 & $<0.001$ \\
\hline
\end{tabular}




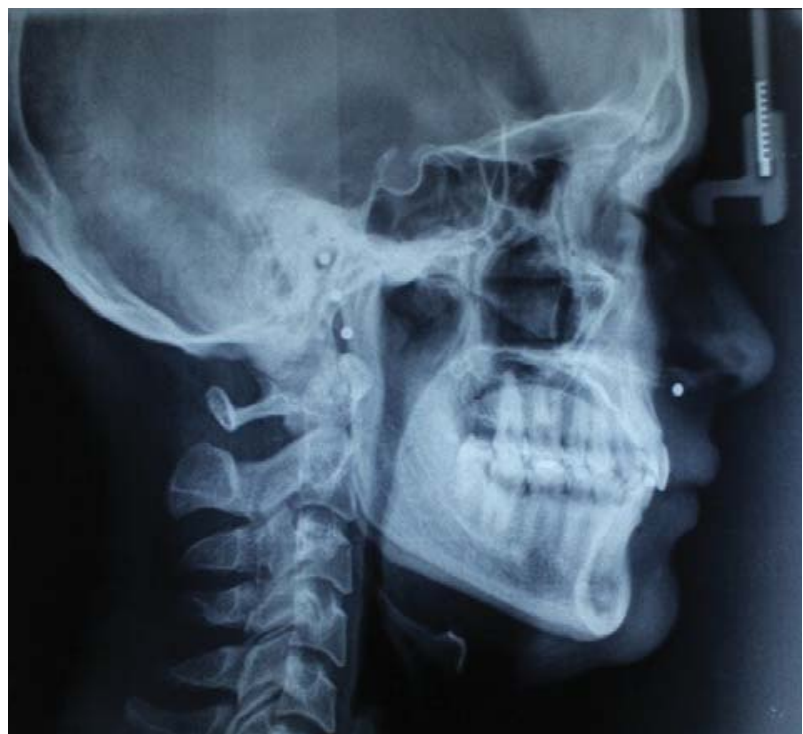

Figure 1: Lateral Cephalometric Radiograph with the metallic balls adhered to the superior border, middle point and inferior border of tragus and lower border of ala of nose

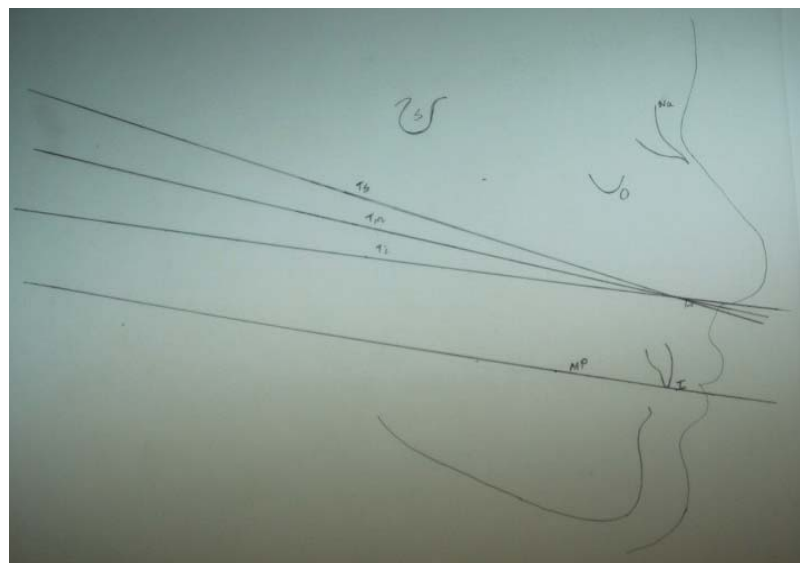

Figure 2: Cephalometric Tracing

\section{Discussion}

Cephalometric line and angle analysis can provide useful information of craniofacial skeleton and the orientation of occlusal plane in both dentulous and edentulous subjects. ${ }^{7-9}$ During fabrication of complete denture, occlusal plane must be orientated in the most acceptable cant for esthetics and function. Investigators have suggested various concepts and methods for orientation of occlusal plane in complete dentures based on morphologic studies on natural and artificial dentitions and on clinical experience. ${ }^{10-13}$ Due to absence of any concrete intraoral and extra oral anatomical landmark, determination of occlusal plane is prone to subjective variation. Anatomical landmarks suggested to clinically determine position of occlusal plane are upper lip, corner of mouth, lateral margins of tongue, two-thirds of height of retromolar pad, parallel to ala-tragus (Camper's line) and interpupillary lines, ${ }^{14}$ parallel to hamular notch-incisive papilla plane, and 3.3 mm below parotid papilla, ${ }^{15,16}$ parallel to and midway between residual ridges ${ }^{17}$. The most widely used method in determining plane of occlusion is ala tragus line method. ${ }^{4}$ However, there are some controversies on exact points of reference of ala-tragus line. ${ }^{6}$

In the present study, the angle formed between occlusal plane and ATm had the lowest mean value of $2.39^{\circ}$. The highest was measured with ATs $5.18^{\circ}$, while the angle formed with ATi was $3.60^{\circ}$. This indicates Ala Tragus middle was closely parallel to occlusal plane compared to other two planes. The findings of this study is similar to study conducted by Bondekar et $\mathrm{al}^{18}$ in which middle border of the tragus was found to be the most appropriate posterior reference point. The middle point on tragus was also recommended as point for establishing occlusal plane in other studies conducted by Augsburger, ${ }^{11}$ Shigli, ${ }^{19}$ Jayachandran, ${ }^{20}$ Landa (1947), Nikzad Javid (1947), Xier and Zhao (1993), Neil and Narin. ${ }^{2122}$

Contradictory to the results obtained in the present study, in the studies by Sadr et al's, ${ }^{23}$ Quaran et al. ${ }^{24}$ and Deogade et $\mathrm{a}^{25}$ superior border of the tragus with the inferior border of the ala of the nose was the most accurate in orienting the occlusal plane. However in the studies by Saquib et al, ${ }^{26}$ Van Niekerk, ${ }^{10}$ Hartono, ${ }^{12}$ Singh $\mathrm{G},{ }^{22}$ Kumar et al.,${ }^{27}$ and Chaturvedi et al.,${ }^{28}$ the line marked from inferior point of tragus to ala of nose was most parallel line with occlusal plane in dentulous subjects compared to the lines from superior and middle point of tragus with ala of nose. 
In the present study using a one sample $\mathrm{t}$ test, it was found that there was a statistically significant difference between the three planes i.e., Ala Tragus superior, Ala Tragus middle and Ala Tragus inferior in relation to the occlusal plane $(p<0.001)$ in total subjects as well as for both males and females which means that using ATm to orient the occlusal plane would make a significant difference in the esthetics and comfort of the complete denture.This indicates that there was no parallelism between the occlusal plane and ala-tragus line with three different posterior ends. This findings is similar to other studies conducted by Sadr et al. ${ }^{23}$ and Quran et al. ${ }^{24}$

As this study was performed in a limited population, results of this study cannot be generalized. So, further detailed survey in larger population is needed.

\section{Conclusion}

Within the limitations of the study, it can be concluded that the ala tragus line drawn from middle point of the tragus of the ear to inferior border of ala of the nose is the most accurate line for the orientation of occlusal plane in edentulous patients.

\section{References}

1. Monteith Brain D. A cephalometric method to determine the angulation of the occlusal plane in edentulous patients. J Prosthet Dent. 1985;54(1):81-7.

2. Karkazis HC, Polyzois GL. Cephalometrically predicted occlusal plane: Implications in removable prosthodontics. J Prosthet Dent. 1991;65(2):258-64.

3. Shone RB CJ. A guide to the orientation of the plane of occlusion. J Prosthet Dent. 1953;3(1):53-65.

4. Levin B SL. Results of a survey of complete denture procedure taught in American and Canadian dental schools. J Prosthet Dent. 1969;22:171-7.
5. The Glossary of Prosthodontic Terms: Ninth Edition. J Prosthet Dent. 2017;117(5):1-105.

6. D'Souza NL, Bhargava K. A cephalometric study comparing the occlusal plane in dentulous and edentulous subjects in relation to the maxillomandibular space. J Prosthet Dent. 1996;75(2):177-82.

7. Ow, RK;Keng SS. A radiographic interpretation of craniofacial reference lines in relation to prosthodontic plane orientation author: J Prosthet Dent. 1986;31:326-34.

8. Ow RKK, Djeng SK, Ho CK. Orientation of the plane of occlusion. J Prosthet Dent. 1990;64(1):31-6.

9. Ow, RK;Djeng, SK;Ho C. The relationships of upper facial proportions and the plane of occlusion to anatomic reference planes. J Prosthet Dent. 1989;61:727-33.

10. Van, Niekerk FW;Miller, VJ;Chem C al. The ala tragus line in complete denture prosthodontics. J Prosthet Dent. 1985;53:67-9.

11. Augsburger R. Occlusal plane relation to facial types. J Prosthet Dent. 1953;3:53-65.

12. Hartono R. The occlusal plane in relation to facial types. J Prosthet Dent [Internet]. 1967;17(6):549-58.Availablefrom:http:// www.sciencedirect.com/science/article/ pii/0022391367901242

13. Ismail YH BJ. Position of the occlusal plane in natural and artificial teeth. J Prosthet Dent. 1968;20:407-11.

14. Zarb G A, Bolender C L, Hickey J C CGC. Boucher's Prosthodontic Treatment for Edentulous Patients. 10th edn St Louis CVMosby,. 1990;1-27.

15. Rich H. Evaluation and registration of the H.I.P. plane of occlusion. Aust Dent J. 27(3):162-8.

16. Foley PF, Latta GH J. A study of the position of the parotid papilla relative to the occlusal plane. J Prosthet Dent. 1985;53(1):124-6.

17. Sinobad D. The position of the occlusal plane in dentulous subjects with various skeletal jawrelationships. J Oral Rehabil. 15(5):489-98.

18. Bondekar,V;Wagh,SB;Attal,PN;Pandey V. Evaluation of relation between occlusal plane and ala-tragus line with help of cephalometry. $\mathrm{J}$ Adv Med Dent Sci Res. 2015;3(6):43-8. 
19. Shigli, K CBR; Jabade J. Validity of soft tissue landmarks in determining the occlusal plane.; 3: J Indian Prosthodont Soc. 2005;3:139-45.

20. Jayachandran S, Ramachandran CR, Varghese R. Occlusal plane orientation: A statistical and clinical analysis in different clinical situations. J Prosthodont. 2008;17(7):572-5.

21. Feng J, Aboyoussef H, Weiner S, Singh S, Jandinski J. The effect of gingival retraction procedures on periodontal indices and crevicular fluid cytokine levels: A pilot study. J Prosthodont. 2006;15(2):108-12.

22. Singh G. Ala Tragus Line - A Cephalometric Evaluation. . Int J Prosthet Dent. 2010;1(1):15.

23. Sadr K, Sadr M. A study of parallelism of the occlusal plane and ala-tragus line. J Dent Res Dent Clin Dent Prospects [Internet]. 2009;3(4):107-9. Available from: http://www. pubmedcentral.nih.gov/articlerender.fcgi?artid $=3463096 \&$ tool $=$ pmcentre $\&$ rendertype $=$ abstr act

24. AL Quran FAM, Hazza'A A, Nahass N Al. The Position of the Occlusal Plane in Natural and Artificial Dentitions as Related to Other Craniofacial Planes. J Prosthodont. 2010;19(8):601-5.

25. PG SD. Lateral cephalometric radiographs: an adjunct in positioning the occlusal plane in natural and atrificial dentitions as related to other craniofacial planes. J Indian Acad Oral Med Radiol. 2011;4(23):620-4.

26. Shaikh SA, Lekha K, Mathur G. Relationship between occlusal plane and three levels of ala tragus line in dentulous and partially dentulous patients in different age groups: A pilot study. J Clin Diagnostic Res. 2015;9(2):ZC39-ZC42.

27. Kumar S, Garg S, Gupta S. A determination of occlusal plane comparing different levels of the tragus to form ala-tragal line or Camper's line: A photographic study. J Adv Prosthodont. 2013;5:9-15.

28. Chaturvedi S, Thombare R. Cephalometrically assessing the validity of superior, middle and inferior tragus points on ala-tragus line while establishing the occlusal plane in edentulous patient. J Adv Prosthodont [Internet]. 2013;5(1):58-66. Available from: http://www. pubmedcentral.nih.gov/articlerender.fcgi?artid $=3597927 \&$ tool $=$ pmcentrez\&rendertype $=$ abstr act. 